\title{
Feed Intake in Atlantic Salmon Fed with or without Surface Spreading of Feed
}

Turid Synnøve Aas ${ }^{1,4^{*}}$, Trine Ytrestøyl ${ }^{1,4}$, Torbjørn Åsgård ${ }^{1,4}$, Kristoffer Rist Skøien ${ }^{2,4}$, Morten Omholt Alver ${ }^{2,3,4}$, Jo Arve Alfredsen ${ }^{2,4}$

$$
\begin{aligned}
& \text { استهلاك سمك السلمون الأطلسي للاعلاف مع أو بدون نشر الاعلاف على } \\
& \text { السطح } \\
& \text { توريد سينوفع,ا ،تورين ترستويع,ا، توربرن اسجاردع,1 ،كرستوفر رستوع,r مورتن اوملت الفرع,ب,r و } \\
& \text { جو ارف الفردسنع, }
\end{aligned}
$$

ABSTRACT. In intensive salmon farming, it is common practice to spread the feed over a large surface area, assuming that spreading of the feed increases feed intake in the fish. However, the impact on the feed pellets during spreading results in feed loss due to pellet breakage. In this study, feed intake, growth and signs of aggressive behavior was compared in salmon fed without or with spreading of the feed on the surface area of the tanks. Atlantic salmon (Salmo salar) with initial body weight $0.6 \mathrm{~kg}$ were kept in $3.3 \mathrm{~m}^{3}$ tanks supplied with sea water (salinity $32 \%$, mean temperature $11^{\circ} \mathrm{C}$ ) for one month. The salmon were fed one meal daily, either by dropping the feed from one point, or by spreading the feed over the water surface. Feed intake and growth was measured. Fin damage was given a score at termination of the trial as a measure of competitive behavior during feeding. The relative feed intake (i.e. percent of body weight per day) in salmon fed without spreading or with spreading of the feed was $0.63 \pm 0.05$ and $0.64 \pm 0.02 \%$, respectively. The growth rate was identical in salmon fed without or with spreading of the feed, and no significant difference in variance in final weight was found. No difference in fin damage for salmon fed without or with spreading of the feed was revealed. The data showed that for the conditions used in this trial, spreading of feed had no influence on feed intake or growth of salmon.

KEYWORDS: Atlantic salmon; Spreading of feed; Feed intake; Feeding behavior.

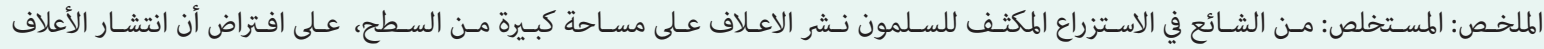

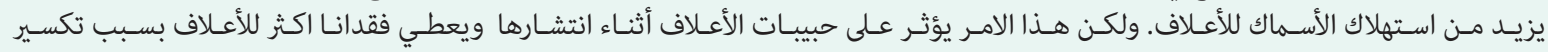

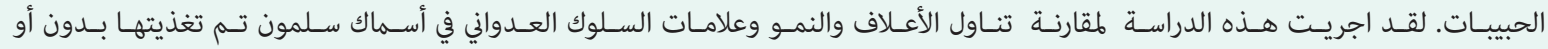

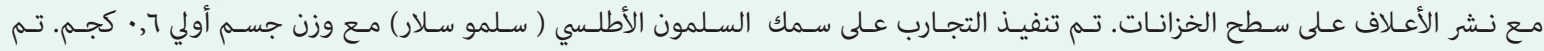

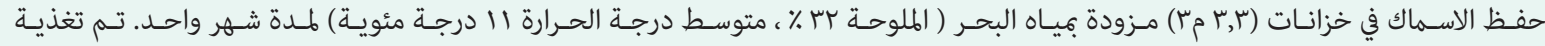

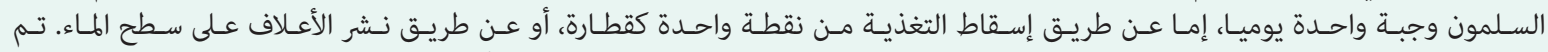

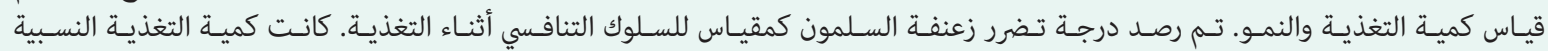

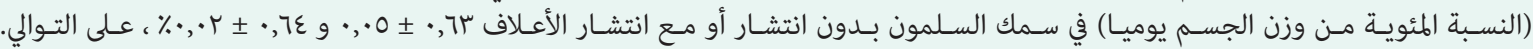

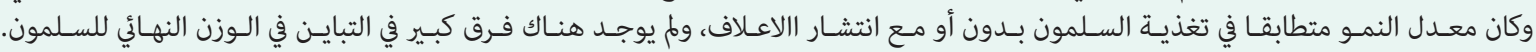

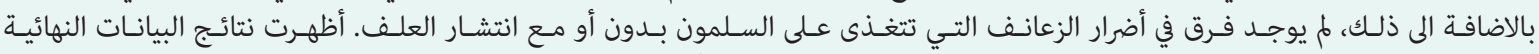

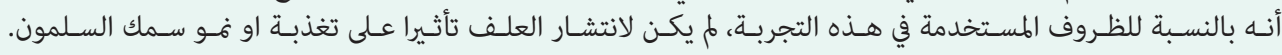

$$
\begin{aligned}
& \text { الكلمات المفتاحية: سمك السلمون، الأطلسي، انتشار الأعلاف، استهلاك العلف، سلوك التغذية }
\end{aligned}
$$

\section{Introduction}

$\mathrm{T}$ he high growth rate of salmon depends on high feed intake, and feed utilization is highest at high feed intake (Einen et al., 1995; Einen et al., 1999; Grisdale-Helland et al., 2013). Thus, high feed intake is required for efficient production in salmon farming. $A$ fish may only respond to a feed particle when it is within

Turid Synnøve Aas ${ }^{1,4^{*}}$ ) synnove.aas@nofima.no,

${ }^{1}$ Nofima, Sjølsengveien 22, NO-6600 Sunndalsøra, Norway, ${ }^{2}$ NTNU Department of Engineering Cybernetics, NO-7491 Trondheim, Norway, ${ }^{3}$ SINTEF Ocean, NO-7465 Trondheim, Norway, ${ }^{4}$ Centre for Research Based Innovation in Aquaculture Technology (CREATE), SFI, SINTEF Sealab, NO-7645 Trondheim, Norway a certain distance from the fish, and to assure high feed intake, feed pellets must be available to each individual fish. In commercial salmon farming, the feed is commonly spread over a large area of the surface, assuming this has a positive effect on feed intake.

In Norwegian salmon farming, the early stages up to smolt of approximately $100 \mathrm{~g}$ have traditionally been kept in land based farms, whereas salmon in the growout phase up to slaughter size is kept in net pens in the sea. In later years the trend is to keep the fish longer in the land based farms, which implies an upscaling of the tanks which may reach $1000 \mathrm{~m}^{3}$ water volume or more (Gorle et al., 2019). Environmental conditions, such as 
Table 1. Measurement of water current $\left(\mathrm{cm} \mathrm{s}^{-1}\right)$ measured below the feeder, $40 \mathrm{~cm}$ from the tank wall and at $30 \mathrm{~cm}$ depth. Data are given as mean and SD $(\mathrm{n}=10)$

\begin{tabular}{lllllll}
\multicolumn{2}{l}{ No spreading } & \multicolumn{5}{c}{ Spreading } \\
Tank number & 208 & 209 & 214 & 207 & 213 & 215 \\
Water current, $\mathrm{cm} \mathrm{s}^{-1}$ & 22 & 23 & 23 & 24 & 23 & 23 \\
& $\mathrm{SD}=4$ & $\mathrm{SD}=3$ & $\mathrm{SD}=3$ & $\mathrm{SD}=6$ & $\mathrm{SD}=3$ & $\mathrm{SD}=2$
\end{tabular}

light, temperature, oxygen levels, salinity and water current affect behavior in salmon in sea cages, and feeding induces the changes in the behavior (reviewed by Oppedal et al., 2011). In tanks, the behavior is restricted by the volume of the tank. Volume and design of the tanks have been shown to affect feed intake and growth in salmon (Espmark et al., 2017; Føre et al., 2018).

In salmon farming in sea cages as well as in land based farms, the feed is usually transported from a storage unit to the cages or tanks with a pneumatic system where the feed is carried by air through a pipe system, and a spreader may be mounted on the outlet of the pipe. Spreading of the pellets can be controlled by adjusting the air stream in the system (Alver et al., 2016; Oehme et al., 2012). Air stream is a main factor for pellet breakage in the feeding system (Aas et al., 2011a), and moderate spreading of feed is therefore advantageous to avoid losses due to pellet breakage. Feeds with physical pellet quality that is optimal for the feeding systems may not be optimal for the fish (Aas et al., 2017; Aas et al., 2011b; Oehme et al., 2014) and losses due to pellet breakage may be weighed against losses due to suboptimal fish growth.

Feed loss also occurs when uneaten feed pellets sink to the bottom of the tank. It is difficult to quantify uneaten feed, but $7 \%$ of the total feed in salmon farming has been suggested (Gjøsæter et al., 2008). Clearly, good feeding routines produce minimal feed spill. Reduced feed utilization and growth also represent losses. As high feed intake is a prerequisite for high feed utilization in salmon (Einen et al., 1995; Einen et al., 1999; Grisdale-Helland et al., 2013), some overfeeding may be necessary to achieve maximum feed intake and feed utilization.

Optimal feeding routines in salmon farming implies minimal pellet breakage and minimal feed spill while maximal feed intake is assured. At fish farms, control of feeding is assisted by camera systems. Models intending to optimize feeding are also derived (Alver et al., 2004; Alver et al., 2016; Skøien et al., 2016). Spreading of feed across the surface is assumed to increase feed intake in fish by making feed available to all individuals and minimize hierarchical behavior during feeding. The manner of feed dispersal influences the equality of access of feed among individuals (reviewed by Attia et al., 2012). At restricted feeding, the aggression level may be high (Jones et al., 2010), and localized feeding may result in larger growth variation among individuals than when feed is dispersed.

Growth and aggression levels related to feed dispersion is poorly documented. As spreading is correlated to pellet breakage (Aas et al., 2011a), such information is crucial in order to optimize feeding routines. In the present study, the effect of spreading of feed on feed intake was tested in $3.3 \mathrm{~m}^{3}$ tanks. Atlantic salmon were fed either from one single point over the tank with no spreading on the water surface, or the feed was spread over a large area of the water surface. Feed intake, growth and signs of competitive behavior (fin erosion) was measured.

\section{Materials and Methods}

\section{Fish Trial}

A tank experiment with Atlantic salmon with mean initial body weight $607 \mathrm{~g}$ was run in for 30 days with approximately 100 fish per tank in triplicate at Nofima's Research Station for Sustainable Aquaculture at Sunndalsøra, Norway. The fish were kept in octahedral tanks (quadratic with the corners 'cut'; $2 \times 2$ m surface and volume $3.3 \mathrm{~m}^{3}$ ) supplied with sea water (salinity $32 \%$ ) in a flow through system with mean water temperature 11.0 ${ }^{\circ} \mathrm{C}$ (SD 1.6, range $7.5-13.4{ }^{\circ} \mathrm{C}$, logged every $5 \mathrm{~min}$ ) and at continuous light.

The feed was distributed with Poro EX 04 automatic feeders (Poro AB, Kåge, Sweden). For tanks with spreading of the feed on the surface, a Poro EX 06 spreader was connected to the feeder, and the spreading area was assumed to cover the whole surface of the tank. For tanks without spreading of the feed on the water surface, the spreader was dismounted, so that the feed fell into the water from the opening of the feeding automat in a small area of a few $\mathrm{cm}^{2}$.

Prior to the trial, the tanks were standardized with regard to water flow $\left(80 \mathrm{~L} \cdot \mathrm{min}^{-1}\right)$, water velocity and spreading of feed. The water current was measured in all tanks just below the feeder, $40 \mathrm{~cm}$ from the tank wall and at $30 \mathrm{~cm}$ depth. The overall mean current was $23 \mathrm{~cm} \cdot \mathrm{s}^{-1}$ (Table 1). In the three tanks with spreading of the feed, each spreader was manually adjusted so that a largest possible area of the tank was covered, but without losing pellets out of the tank.

As pellets met the water surface, they started to sink and followed the circular water current until they settled on the tank bottom. During this movement through the 
water volume, the feed was available for the fish. After some circular movements on the tank bottom, the pellets followed the water flow out of the outlet in the center in the bottom of the tank.

The spreading of pellets in time was measured by running the feeding system for $3 \mathrm{~s}$ in one tank without and one tank with spreader, with no fish in the tanks. The time (s) from start of feeding to the first and the last pellet reached the bottom of the tank was recorded ( $n=10$, Table 2). The difference between first and last pellets, which expresses the time the feed was in the water column, was 12 and $15 \mathrm{~s}$ in a tank without and with spreading, respectively. The difference was not significant with ANOVA $(\mathrm{P}<0.05)$.

The salmon were fed a commercial feed with pellet size $4.5 \mathrm{~mm}$ (Skretting Supreme, Skretting, Stavanger, Norway). The physical properties of the feed are shown in Table 3. The fish was fed one meal daily, lasting from 9 to $10 \mathrm{AM}$. The feed intake was estimated by collecting and weighing uneaten feed and measuring dry matter. The recovery (\%) of uneaten feed was estimated by following the same routine as in the trial, but with no fish in the tanks.

The recovery value was used to correct the amount of uneaten feed, and daily feed intake was calculated as feed given minus corrected uneaten feed (Helland et al. 1996). All tanks were fed the same amount of feed, and the size of the ration was adjusted daily based on the last three days' feed intake aiming at $20 \%$ overfeeding in the tanks with highest feed intake.

\section{Sampling}

At start and end of the trial, biomass was recorded and the fish counted. At termination of the trial, the individual weight of 30 fish from each tank was also registered. The fin damage of these 30 fish was evaluated by a scoring system where dorsal, caudal, pelvic and pectoral fins were given an integer score from 0 (no visible damage) to 4 (severe damage), and damages were classified as fin erosion, split fin, deformed fin, hemorrhage or asymmetric fins. At handling and weighing, the fish were sedated with Aqui-S ${ }^{\circledast}$ (clove oil, isoeugenol 2-5 $\mathrm{mg} \mathrm{L}^{-1}$ ).

\section{Measurement of Physical Feed Quality}

Diameter and length of the pellets were measured with an electronic caliper. Bulk density was measured by loosely pouring the feed from a funnel into a $1000 \mathrm{ml}$ measuring cylinder. Sinking velocity was measured in a $1.3 \mathrm{~m}$ high cylinder with tight bottom and filled with $34 \%$ sea water at $10^{\circ} \mathrm{C}$ and start and end of $1 \mathrm{~m}$ distance marked on the outside. The time the pellets used for sinking $1 \mathrm{~m}$ was recorded for one pellet at a time.

\section{Calculation}

Feed intake, given on dry matter (DM) basis, was estimated according to Helland et al. (1996).
Feed Intake $(\mathrm{g}, \mathrm{DM})=$ Feed Fed $(\mathrm{g}, \mathrm{DM})-\frac{\text { Uneaten Feed }(\mathrm{g}, \mathrm{DM})}{\text { Recovery }}$

(1)

Recovery was estimated by following the experimental feeding routines, but with no fish in the tanks:

Recovery $=\frac{\text { Feed Spill }(\mathrm{g}, \mathrm{DM})}{\text { Feed Used }(\mathrm{g}, \mathrm{DM})}$

(2)

Weight Gain $(\%)=100 \times \frac{\text { Final Weight }(\mathrm{g})-\text { Initial Weight }(\mathrm{g})}{\text { Initial Weight }(\mathrm{g})}$

(3)

The relative feed intake ( $\mathrm{RFI}, \%$ of body weight per day) and specific growth rate (SGR, \%) and thermal growth coefficient (TGC) are calculated from the following equations as:

$$
\text { RFI }=100 \times \frac{\text { Feed Intake }(\mathrm{g}, \mathrm{DM})}{\text { Days Fed }\left[\frac{\text { Initial Weight }(\mathrm{g})+\text { Final Weight }(\mathrm{g})}{2}\right]}
$$

$$
\operatorname{SGR}(\%)=\frac{100 \times[\ln (\text { Final Weight })-\ln (\text { Initial Weight })]}{\text { Days Fed }}
$$

$$
\mathrm{TGC}=1000 \times \frac{(\text { Final Weight })^{1 / 3}-(\text { Initial Weight })^{1 / 3}}{\text { Sum Daydegrees }}
$$

where, Sum daydegrees $=$ Number of days in trial $\times$ Mean temperature $\left({ }^{\circ} \mathrm{C}\right)$

\section{Statistical Analysis}

Tank data were analyzed with one-way ANOVA (t-test). Individual data were compared with a hierarchical (nested) ANOVA using the 'Nested' procedure in SAS. The score data (individual data) were also analyzed with a nested ANOVA after arcsine transformation of the score data divided by 4 (to obtain data in the range $0-1$ ). ANOVA of original data and transformed data gave corresponding results. Variance among treatments was analyzed by comparing the standard deviations with oneway ANOVA. A significance level of $a=0.05$ was used for all statistical analyses. Statistical analyses were per- 
Table 2. Time(s) from start of feeding till first and last pellet reached the tank bottom, and the difference, at $3 \mathrm{~s}$ feeding in one tank without and one tank with spreading and with no fish in the tank. Data are given as mean and SD $(n=10)$

$\begin{array}{lll} & \text { Without spreading } & \text { With spreading } \\ \text { First pellet } & 7 \mathrm{SD}=1 & 7 \mathrm{SD}=1 \\ \text { Last pellet } & 19 \mathrm{SD}=5 & 22 \mathrm{SD}=4 \\ \text { Difference } & 12 \mathrm{SD}=4 & 15 \mathrm{SD}=5\end{array}$

formed with the SAS 9.4 computer software (SAS, USA).

\section{Results}

There was no mortality in the trial and the fish appeared to be at good health. There were no significant differences in feed intake or growth. The total feed intake was $132 \pm 10$ and $127 \pm 1 \mathrm{~g}$ (dry matter basis) per individual in salmon fed without or with spreading of the feed, respectively. The relative feed intake (\% of body weight per day) in salmon fed without spreading or with spreading of the feed was $0.63 \pm 0.05 \%$ and $0.64 \pm 0.02 \%$, respectively. The growth rate was $0.97 \%$ per day for both groups (Table 4).

Comparing the body weight of 30 individual fish from each tank did not reveal any effect of spreading the feed on variance in body weight (Table 5). No significant effect of spreading the feed was found on scoring of fin damage (Table 6). The damage on the dorsal fins was mainly fin erosion and some split fins and deformed fins. The damage on the caudal fins was also mainly classified as fin erosion, but some split fins and red spots were also present. For pectoral fins, split fins were the most common damage, followed by fin erosion and red spots. For pelvic fins, there were very little damage except some split fins. In one tank (tank number 215, with spreading of feed), several fish had red spots in the skin. The reason for this is unknown. In the other tanks, the fish generally appeared normal for salmon of this size kept in tanks.

\section{Discussion}

A tank experiment was chosen to test whether spreading of the feed affects feed intake in Atlantic salmon. Compared to experiments in sea cages, a tank experiment has the advantages that spreading of feed, feed intake and growth can be measured with high accuracy, and it can be run at a relatively low cost. Data from small scale studies are not necessarily valid for large scale conditions (Espmark et al., 2017). As for all trials, the data from the present study are only representative for the conditions used in this study.

There was large difference in spreading pattern on the water surface depending on whether the feed was spread or not, which represents spreading in space. Feed is also spread in time, and the feed is available for the salmon while sinking through the water. Numerically, spreading of the feed on the water surface resulted in a longer time in the water (Table 2), although this was not significantly different $(P<0.05)$ from the time the pellets were in the water when feeding from one point. There was some variation in these measurements as all pellets follow different routes through the water column. There was a difference among pellets in sinking velocity (Skøien et al., 2016). The 10 replicates did not reveal any significant difference in spreading in time.

The overall mean SGR was $0.97 \%$ per day, which is in accordance with (Austreng et al., 1987) or just below (Skretting, 2011) expected growth of salmon of this size at this temperature. According to Skretting (2011), Atlantic salmon of 600 and $800 \mathrm{~g}$ are expected to grow 1.28 and $1.14 \%$ per day, respectively, at $11{ }^{\circ} \mathrm{C}$. A period of one or two weeks for acclimation to new conditions is normal in salmon trials. This was also observed in the present trial, where the feed intake was moderate, but gradually increasing, during the first ten days. Thereafter, the feed intake was as expected, and the overall growth in the trial was only slightly below expected values. It can therefore be assumed that the feed intake and growth was at normal levels during the last 20 days of the trial.

The feed intake was very similar in both treatment groups, showing that in this trial, spreading of the feed on the water surface did not affect the mean feed intake in salmon. Spreading the feed on the water surface is generally believed to reduce variance in feed intake and correspondingly, body weight, in fish (Attia et al., 2012; Ryer and Olla, 1996). This is assumed to be due to that feeding from one point may favor the most dominant individuals whereas when spreading the feed, it is available to all individuals. The variation in individual body weight when salmon were fed without spreading versus with spreading the feed was measured by comparing the standard deviations. An ANOVA of these standard deviations did not indicate any effect of spreading of the feed on variation in final body weight. The individual body weight at start was not measured because this require extra handling of the fish, which imply extra stress to the fish, which again may lead to reduced feed intake in the trial. The variation in body weight at start of the trial was assumed to equal in both treatment groups as fish was allocated randomly to the experimental tanks. The salmon was fed full ration in the present trial, whereas at restricted feeding, competitive behavior may result in larger differences in feed intake when the fish is fed

Table 3. Pellet length and diameter, bulk density and sinking velocity of the feed used in the trial (Mean and SD)

\begin{tabular}{|c|c|}
\hline \multicolumn{2}{|c|}{ Physical properties of the feed } \\
\hline Pellet diameter (mm) & $4.6 S D=0.3(n=20)$ \\
\hline Pellet length (mm) & $7.5 \mathrm{SD}=1.0(n=20)$ \\
\hline Bulk density $\left(\mathrm{g} \mathrm{L}^{-1}\right)$ & $650 S D=2.1(n=3)$ \\
\hline Sinking velocity $\left(\mathrm{m} \mathrm{s}^{-1}\right)$ & $11.2 \mathrm{SD}=0.9(\mathrm{n}=20)$ \\
\hline
\end{tabular}


Table 4. Body weight, growth and feed intake in Atlantic salmon fed without or with spreading of the feed on the water surface

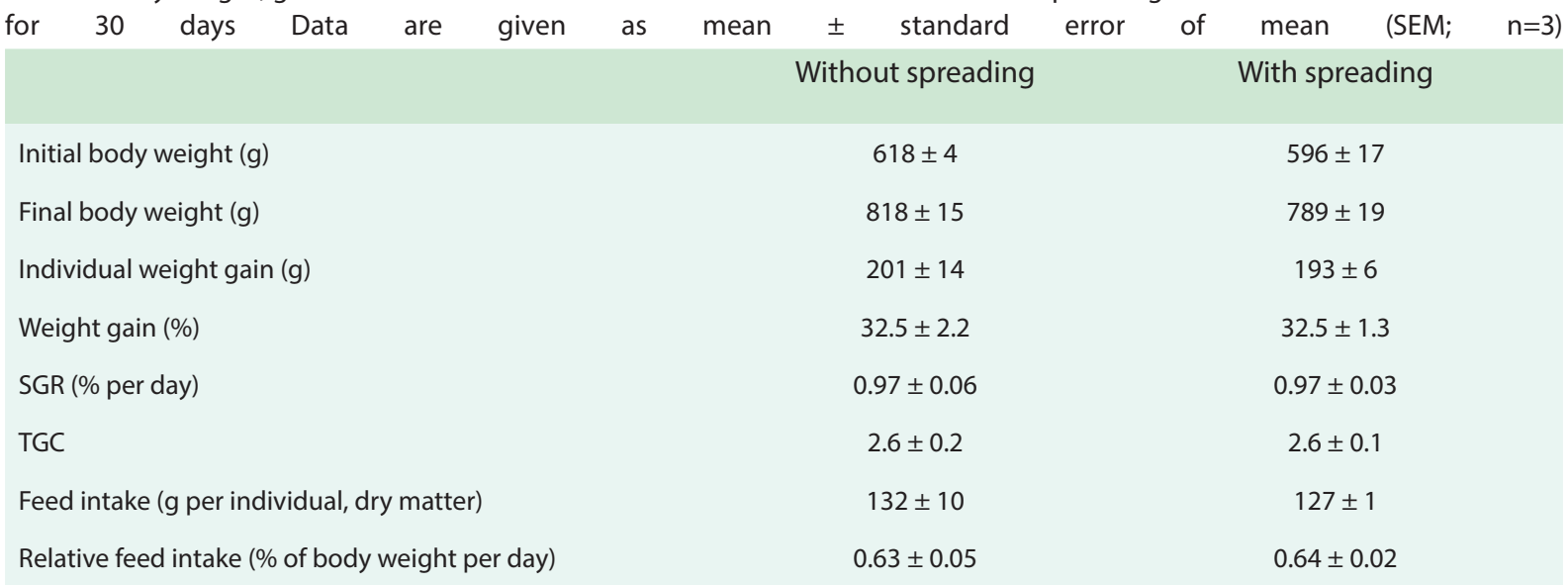

without spreading of feed than when the feed is spread (Juell, 1995; Ryer and Olla, 1996).

The trial was not designed as a growth trial. To reveal significant effects of growth in salmon, a doubling in weight during the experiment is often used as a rule of thumb. In the present trial, the growth was 32.5\%. There was a slight difference in body weight in the two treatment groups, but the TGC, which is independent of body size, was also identical in salmon fed with or without spreading of feed. Since the growth rate was exactly the same in both treatment groups, it can be concluded that spreading of the feed did not affect growth.

Scoring of fin damage was used as a measure of hierarchical, aggressive behavior. Restricted feeding has been shown to increase fin damage in Atlantic salmon (Noble et al., 2008). With the two feeding patterns used in the present trial, no differences in score of fin damage were found. Spatially concentrated feed delivery is believed to increase competition (Juell, 1995; Symons, 1971) but this effect may not be seen due to the overfeeding in the present study. This, together with feed intake and body weight data, indicates that there is no need for using the feed spreader under the conditions used in this trial if feed is sufficiently available. As all handling and spreading of feed increases the risk of pellet breakage (Aas et al., 2011a), the feed should rather be distributed from one point, without the spreader.
The spreading of feed in time in the water volume is related to the sinking velocity of the feed. Furthermore, pellet size will affect spreading of the feed in the water volume, since small pellets will be scattered in the water compared to larger pellets where the feed is concentrated in larger particles. Such factors can be taken into account to adjust spreading of feed, in addition to spreading on the surface.

The response distance in fish, which is the maximum distance fish responds to a feed particle, depends on several factors, such as fish species, fish size, swimming speed, light conditions, water turbidity, characteristics of the feed and experimental conditions. Response distances in the range $5-25 \mathrm{~cm}$ have been measured for large fish (60 $\mathrm{cm}$ and larger) of different species under variable experimental conditions (summarized by Richmond et al., 2004). In a fish tank of limited volume and with feed following the movement of the swirl as in the present study, the fish has a high probability of being within this distance of some of the feed particles during a meal. In a large sea cage, even when spreading the feed over a large area, the density of feed particles is considerably smaller in most of the cage volume (Alver et al., 2004; Alver et al., 2016; Skøien et al., 2016), and feeding behavior with high swimming activity is probably necessary for the fish to be able to feed to satiation. In a sea cage with circumference $150 \mathrm{~m}$ or more and variable wind and water

Table 5. Final body weight of 30 randomly selected individuals from each tank of Atlantic salmon fed without or with spreading of the feed on the water surface for 30 days

\begin{tabular}{lcccccc} 
& \multicolumn{3}{c}{ No spreading } & & \multicolumn{2}{c}{ Spreading } \\
Tank number & 208 & 209 & 214 & 207 & 213 & 215 \\
Mean weight (g) & 782 & 771 & 851 & 779 & 165 & 148 \\
SD & 207 & 188 & 197 & 163 & 1255 & 1436 \\
Maximum (g) & 1132 & 1358 & 1289 & 1052 & 479
\end{tabular}


Table 6. Scoring of fin damage in 30 randomly selected individuals from each tank of Atlantic salmon fed without or with spreading of the feed on the water surface for 30 days. Damage of each fin was given a score from 0 (no visible damage) to 4 (severe damage). Data are given as mean \pm SEM., where SEM is calculated from the pooled standard deviation of data from

\begin{tabular}{llll} 
all individuals & \multicolumn{1}{c}{$(\mathrm{n}=90)$} & within & each treatment \\
& Without spreading & With spreading \\
Dorsal fin & $2.0 \pm 0.1$ & $1.8 \pm 0.1$ \\
Caudal fin & $1.8 \pm 0.1$ & $1.7 \pm 0.1$ \\
Pectoral fins & $1.6 \pm 0.1$ & $1.5 \pm 0.1$ \\
Pelvic fins & $0.6 \pm 0.1$ & $0.5 \pm 0.1$
\end{tabular}

current, the effect of spreading versus no spreading of feed may be different from the data obtained in a tank experiment. Since feed pellets are prone to breaking upon spreading (Aas et al., 2011a) the feed should not be spread needlessly. To optimize feeding routines, it is therefore necessary to measure the effect of spreading the feed in large-scale sea cages also.

\section{Conclusion}

No significant differences in feed intake or growth were found in salmon fed from one point or feed spread over the water surface in $3.3 \mathrm{~m}^{3}$ experimental tanks. Neither was there any effect of spreading of the feed on variation in body weight, or in fin damage. In the present trial thus, spreading the feed on the water surface did not improve any of the measured parameters compared to feeding the fish from one point.

\section{Acknowledgements}

The staff at Nofima's Research Station for Sustainable Aquaculture at Sunndalsøra, and especially Frode Nerland, is acknowledged for running the fish trial, and Roger Selset for technical advice. This study was funded by the Centre for Research-Based Innovation in Aquaculture Technology (CREATE) and their partners.

\section{References}

Aas TS, Oehme M, He G, Sørensen M, Lygren I, Åsgård T. (2011a). Analysis of pellet degradation of extruded high energy fish feeds with different physical qualities in a pneumatic feeding system. Aquacultural Engineering 44(1): 25-34.

Aas TS, Sixten HJ, Hillestad M, Sveier H, Ytrestøyl T, Hatlen B, Åsgård T. (2017). Measurement of gastrointestinal passage rate in Atlantic salmon (Salmo salar) fed dry or soaked feed. Aquaculture Reports 8: 49-57.
Aas TS, Terjesen BF, Sigholt T, Hillestad M, Holm J, Refstie S, Baeverfjord G, Rørvik K-A, Sørensen M, Oehme M . (2011b). Nutritional responses in rainbow trout (Oncorhynchus mykiss) fed diets with different physical qualities at stable or variable environmental conditions. Aquaculture Nutrition 17: 657-670.

Alver MO, Alfredsen JA, Sigholt T. (2004). Dynamic modelling of pellet distribution in Atlantic salmon (Salmo salar L.) cages. Aquacultural Engineering 31(1-2): 51-72.

Alver MO, Skøien KR, Føre M, Aas TS, Oehme M, Alfredsen JA. (2016). Modelling of surface and 3D pellet distribution in Atlantic salmon (Salmo salar L.) cages. Aquacultural Engineering 72-73: 20-29.

Attia J, Millot S, Di-Poï C, Bégout ML, Noble C, Sanchez-Vazquez FJ, Terova G, Saroglia M, Damsgård B. (2012). Demand feeding and welfare in farmed fish. Fish Physiology and Biochemistry 38(1): 107-118.

Austreng E, Storebakken T, Åsgård T. (1987). Growth rate estimates for cultured Atlantic salmon and rainbow trout. Aquaculture 60(2): 157-160.

Einen O, Holmefjord I, Åsgård T, Talbot C. (1995). Auditing nutrient discharges from fish farms: theoretical and practical considerations. Aquaculture Research 26: 701-713.

Einen O, Mørkøre T, Thomassen MS. (1999). Feed ration prior to slaughter - a potential tool for managing product quality of Atlantic salmon (Salmo salar). Aquaculture 178(1-2): 149-169.

Espmark ÅM, Kolarevic J, Åsgård T, Terjesen BF. (2017). Tank size and fish management history matters in experimental design. Aquaculture Research 48(6): 2876-2894.

Føre M, Alver MO, Alfredsen JA, Senneset G, Espmark $\AA$, Terjesen BF. (2018). Modelling how the physical scale of experimental tanks affects salmon growth performance. Aquaculture 495: 731-737.

Gjøsæter J, Otterå H, Slinde E, Nedreaas K, Ervik A. (2008). Effekter af spillfôr på marine organismer. Bergen, Institute of Marine Research, Norway. Annual series. No. 1.11 (in Norwegian).

Gorle JMR, Terjesen BF, Summerfelt ST. (2019). Hydrodynamics of Atlantic salmon culture tank: Effect of inlet nozzle angle on the velocity field. Computers and Electronics in Agriculture 158: 79-91.

Grisdale-Helland B, Lemme A, Helland SJ. (2013). Threonine requirement for maintenance and efficiency of utilization for threonine accretion in Atlantic salmon smolts determined using increasing ration levels. Aquaculture 372-375: 158-166.

Helland SJ, Grisdale-Helland B, Nerland S. (1996). A simple method for the measurement of daily feed intake of groups of fish in tanks. Aquaculture 139(1-2): 157-163. 
Jones HaC, Hansen LA, Noble C, Damsgård B, Broom DM, Pearce GP. (2010). Social network analysis of behavioural interactions influencing fin damage development in Atlantic salmon (Salmo salar) during feed-restriction. Applied Animal Behaviour Science 127(3): 139-151.

Juell JE. 1995. The behaviour of Atlantic salmon in relation to efficient cage-rearing. Reviews in Fish Biology and Fisheries 5(3): 320-335.

Noble C, Kadri S, Mitchell DF, Huntingford FA. (2008). Growth, production and fin damage in cage-held $0+$ Atlantic salmon pre-smolts (Salmo salar L.) fed either a) on-demand, or b) to a fixed satiation-restriction regime: Data from a commercial farm. Aquaculture 275(1): 163-168.

Oehme M, Aas TS, Olsen HJ, Sørensen M, Hillestad M, Li Y, Åsgård T. (2014). Effects of dietary moisture content of extruded diets on physical feed quality and nutritional response in Atlantic salmon (Salmo salar). Aquaculture Nutrition 20: 451-465.

Oehme M, Aas TS, Sørensen M, Lygren I, Åsgård T. (2012). Feed pellet distribution in a sea cage using pneumatic feeding system with rotor spreader. Aquacultural Engineering 51: 44-52.
Oppedal F, Dempster T, Stien LH. (2011). Environmental drivers of Atlantic salmon behaviour in sea cages: A review. Aquaculture 311(1-4): 1-18.

Richmond HE, Hrabik TR, Mensinger AF. (2004). Light intensity, prey detection and foraging mechanisms of age 0 year yellow perch. Journal of Fish Biology 65(1): 195-205.

Ryer CH, Olla BL. (1996). Growth depensation and aggression in laboratory reared coho salmon: the effect of food distribution and ration size. Journal of Fish Biology 48(4): 686-694.

Skretting. Fiskeføde [Internet]. Stavanger, Norway: Skretting; (2011) Available from: http://www.Fwww. skrettingguidelines.com (In Norwegian) (accessed 12 july 2019).

Skøien KR, Aas TS, Alver MO, Romarheim OH, Alfredsen JA. (2016). Intrinsic settling rate and spatial diffusion properties of extruded fish feed pellets. Aquacultural Engineering 74: 30-37.

Symons PEK. (1971). Behavioural adjustment of population density to available food by juvenile Atlantic salmon. Journal of Animal Ecology 40(3): 569-587. 